\title{
Cranial Nerve Preservation Following Surgical Treatment for Epidermoid Cysts of the Posterior and Middle Fossae
}

\author{
Kurt Grahnke ${ }^{1}$ Daniel Burkett ${ }^{2}$ Daphne Li $^{1} \quad$ Caroline Szujewski $^{1}$ John P. Leonetti ${ }^{1}$ \\ Douglas E. Anderson ${ }^{1}$
}

${ }^{1}$ Departments of Neurological Surgery and Otolaryngology, Head and Neck Surgery, and Stritch School of Medicine, Loyola University Chicago, Health Sciences Campus, Maywood, Illinois, United States

2 Department of Neurological Surgery, University of Wisconsin

Hospitals and Clinics, Madison, Wisconsin, United States
Address for correspondence Douglas E. Anderson, MD, Department of Neurological Surgery, Loyola University Chicago, Stritch School of Medicine, $2160 \mathrm{~S} 1^{\text {st }}$ Avenue, Maywood, IL 60153, United States (e-mail: DAnder1@lumc.edu).

J Neurol Surg B 2018;79:445-450.

\begin{abstract}
Keywords

- epidermoid cysts

- cranial nerve preservation

- skull base surgery

- gross total resection

- subtotal resection

Epidermoid cysts are rare lesions, accounting for 0.2 to $1.8 \%$ of all intracranial tumors. They most commonly occur in the cerebellopontine angle where they may cause a breadth of neurologic complications due to mass effect on the nearby cranial nerves $(\mathrm{CN})$, vascular structures, and the brain stem. Treatment of epidermoid cysts is surgical, with the goal of complete resection using microsurgical technique and even more importantly preservation of the involved CNs, vasculature, and brain parenchyma. Successful surgery can result in total resolution of symptoms, but, in certain situations, may not be advisable due to adherence, scarring, or inflammation making dissection of $\mathrm{CN}$ fascicles difficult and possibly hazardous. We conducted a retrospective review from 1998 to 2016 and compiled a series of 28 skull base epidermoid cysts operated on at our institution. Cases were evaluated for presenting symptoms, history of prior resection, and postoperative results including $\mathrm{CN}$ function, extent of resection, residual tumor, and need for reoperations. The average tumor size (largest diameter) was $3.9 \mathrm{~cm}$ with a range of 1 to $7 \mathrm{~cm}$. Eighteen of twenty-eight (64\%) patients underwent a gross total resection and ten underwent subtotal resection. No patients, whether presenting with $\mathrm{CN}$ deficits or not, experienced permanent worsening of $\mathrm{CN}$ function following surgery. Complete resection of epidermoid cysts should remain a high priority of therapy, but, in our opinion, preservation of $\mathrm{CN}$ function should be a primary goal, determining the extent of resection to provide patients with the highest quality of life possible following surgery.
\end{abstract}

\section{Introduction}

Epidermoid cysts are rare lesions, accounting for $0.2 \%$ to $1.8 \%$ of all intracranial tumors. ${ }^{1}$ Their most common location is the cerebellopontine angle (CPA) where they may cause neurologic complications due to mass effect on the nearby cranial nerves $(\mathrm{CN})$, vascular structures, and the brain stem. ${ }^{1-4}$ Presenting symptoms frequently include hearing loss, dizziness, gait disturbance, trigeminal neuralgia, headache, tinnitus, and, if

received

July 18,2017

accepted after revision

November 19, 2017

published online

January 9, 2018

disseminated, hydrocephalus. ${ }^{1,4-6}$ Treatment of epidermoid cysts is surgical, with a desired goal of complete resection using microsurgical technique, but with the preservation of the involved $\mathrm{CN}$, vasculature, and brain parenchyma being of priority. Successful surgery can result in total resolution of symptoms, but in certain situations may not be advisable due to adherence, scarring, or inflammation making dissection of $\mathrm{CN}$ fascicles difficult and possibly hazardous. ${ }^{1-3,7,8}$

(c) 2018 Georg Thieme Verlag KG Stuttgart · New York
DOI https://doi.org/ 10.1055/s-0037-1617431. ISSN 2193-6331. 
Incompletely resected epidermoid cysts tend to recur, but years may elapse prior to the appearance of new symptoms. $^{1,3}$ magnetic resonance imaging (MRI) surveillance should be maintained in all cases indefinitely due to potential late recurrences. ${ }^{4}$ Nonetheless, we believe that preservation of involved $\mathrm{CN}$ should be a primary goal, ultimately determining the extent of resection. With consistent longterm follow-up, recurrent or residual epidermoid cysts can be successfully and safely managed with subsequent surgeries as necessary.

\section{Methods}

We conducted a retrospective review of patients referred to the department of neurological surgery at Loyola University Medical Center for the management of skull base epidermoid cysts from 1998 to 2016 and compiled a series of 28 patients who underwent operative management. Cases were evaluated for presenting symptoms, history of prior resection (at outside institutions), postoperative results including $\mathrm{CN}$ function, extent of resection, and need for reoperation. Tumor size was recorded as largest diameter in any dimension on radiographic imaging.

Surgical approach varied based on location, direction of extension, and size. The aim of surgery was maximum safe resection with an emphasis on preservation of $\mathrm{CN}$ to give our patients the highest quality of life possible following surgery. To achieve $\mathrm{CN}$ preservation, we utilized several different skull base approaches, which would give us maximum exposure of the tumor. Further, $\mathrm{CN}$ monitoring was used in all cases to guide the resection. Extent of resection was in part planned preoperatively based on MRI or computed tomography (CT) scans, but ultimately decided intraoperatively when a tumor's adherence to critical structures could be best ascertained.

\section{Results}

\section{Presentation}

Twenty-eight patients underwent a total of 43 surgeries for epidermoid cyst resection. Twenty-four patients presented to us for a primary resection, whereas four patients came to us after having undergone surgery at outside hospitals. The average age at the time of primary resection was 38.5 years old (range 10-67 years) and the majority of patients were female $(n=20,71 \%)$.

The most common presenting symptoms were headache ( $n=9,32 \%)$, dizziness $(n=5,18 \%)$, and gait disturbances $(n=5,18 \%)$. Fifteen patients $(54 \%)$ presented with a CN deficit ( - Table 1). Of these patients, the most common CN involved were CN VIII ( $n=7,47 \%), \mathrm{CN} \mathrm{V}(n=5,33 \%)$, and CN IX/X ( $n=3,20 \%)$. Patients who presented to us after

Table 1 Patients with cranial nerve deficits at presentation and main outcomes

\begin{tabular}{|c|c|c|c|c|}
\hline Patient & Cranial nerve deficit at presentation & $\begin{array}{l}\text { Cranial } \\
\text { nerve }\end{array}$ & $\begin{array}{l}\text { Extent of } \\
\text { resection }\end{array}$ & Cranial nerve status postoperatively \\
\hline 1 & $\begin{array}{l}\text { Facial numbness (intact corneal } \\
\text { response, HB 3) }\end{array}$ & 5 & GTR & Baseline (HB 3) \\
\hline 2 & $\begin{array}{l}\text { Diplopia, trouble swallowing, facial } \\
\text { paresthesias }\end{array}$ & $3,5,9,10$ & GTR & Baseline \\
\hline 3 & $\begin{array}{l}\text { Hearing loss, tinnitus, facial numbness } \\
\text { (intact corneal response) }\end{array}$ & 5,8 & GTR & Improved facial sensation \\
\hline 4 & 6th nerve palsy, diplopia & 6 & GTR & Baseline \\
\hline 5 & Difficulty swallowing & 9,10 & GTR & Baseline \\
\hline 6 & Facial weakness & 7 & GTR & Baseline \\
\hline 7 & $\begin{array}{l}\text { Profound right-sided hearing loss (AAO- } \\
\text { HNS Grade D) }\end{array}$ & 8 & GTR & $\begin{array}{l}\text { Baseline } \\
\text { (AAO-HNS Grade D) }\end{array}$ \\
\hline 8 & $\begin{array}{l}\text { Profound hearing loss (AAO-HNS Grade } \\
\text { D) }\end{array}$ & 8 & GTR & $\begin{array}{l}\text { Improved } \\
\text { (AAO-HNS Grade A) }\end{array}$ \\
\hline 9 & Diplopia & $3,4,6$ & GTR & Baseline \\
\hline 10 & FN palsy (HB 6) & 7 & STR & Improved (HB 3) \\
\hline 11 & $\begin{array}{l}\text { Facial numbness and pain (HB 2), slight to } \\
\text { mild hearing loss } \\
\text { (AAO-HNS Grade A) }\end{array}$ & 5,8 & STR & $\begin{array}{l}\text { Improved } \\
\text { facial sensation and pain (HB 1), Hearing } \\
\text { preserved (AAO-HNS Grade A) }\end{array}$ \\
\hline 12 & Facial pain & 5 & STR & Improved \\
\hline $13^{\mathrm{a}}$ & $\begin{array}{l}\text { Facial nerve palsy (HB 6), hearing loss, } \\
\text { swallowing difficulty }\end{array}$ & $7,8,9,10$ & STR & Improved swallowing \\
\hline $14^{\mathrm{a}}$ & Diplopia & $3,4,6$ & STR & Improved \\
\hline $15^{\mathrm{a}}$ & Facial twitching (HB 2) & 7 & STR & Improved (HB 1) \\
\hline
\end{tabular}

Abbreviation: AAO-HNS, American Academy of Otolaryngology-Head and Neck Surgery; GTR, Gross-total resection; STR, Subtotal resection.

a signifies prior treatment at outside hospital. 
having undergone surgery at outside hospitals tended to present with more severe symptoms including trouble breathing, facial nerve paralysis, aseptic meningitis, and debilitating headaches.

\section{Intraoperative}

All tumors were located in the posterior $(n=24)$ and middle fossae $(n=4)$. Average tumor size was $3.9+/-1.5 \mathrm{~cm}(\mathrm{~cm})$ with a range of 0.9 to $7 \mathrm{~cm}$ in longest diameter. All tumors had multiple $\mathrm{CN}$ in the surgical field (III-XII) with $\mathrm{CN} \mathrm{V}-\mathrm{X}$ being the most frequent, as was reflected in the patients' symptomatology (-Fig. 1). Additionally tumors tended to abut critical brain regions such as the brain stem, thalamus, and hypothalamus, causing significant clinical deficits (-Fig. 2). To achieve maximum safe resection while preserving critical $\mathrm{CN}$ and brain parenchyma, several different skull base approaches were carefully selected (-Table $\mathbf{2}$ ).

\section{Outcomes}

Eighteen patients (64\%) underwent a gross total resection (GTR) and 10 (36\%) underwent a subtotal resection (STR). Seven of ten patients with STR had a recurrent epidermoid cyst that required reoperation at an average of 40 months with a range of 9 to 72 months after the primary surgery. One patient required a third operation and another patient required a fourth operation. The mean tumor size of the reoperations was $2.9+/-1.8 \mathrm{~cm}$, compared with an average of $3.6+/-1.9 \mathrm{~cm}$ for the initial surgery of this subcohort. All patients with known residual tumors continue to follow up with us in clinic and receive routine MRI or CT surveillance.

Eight of fifteen patients presenting with $\mathrm{CN}$ deficits had improved $\mathrm{CN}$ function postoperatively, while the other seven patients remained stable. Two patients presented with complete facial palsy (House-Brackmann VI), one of whom was able to improve House-Brackmann III postoperatively. Patients

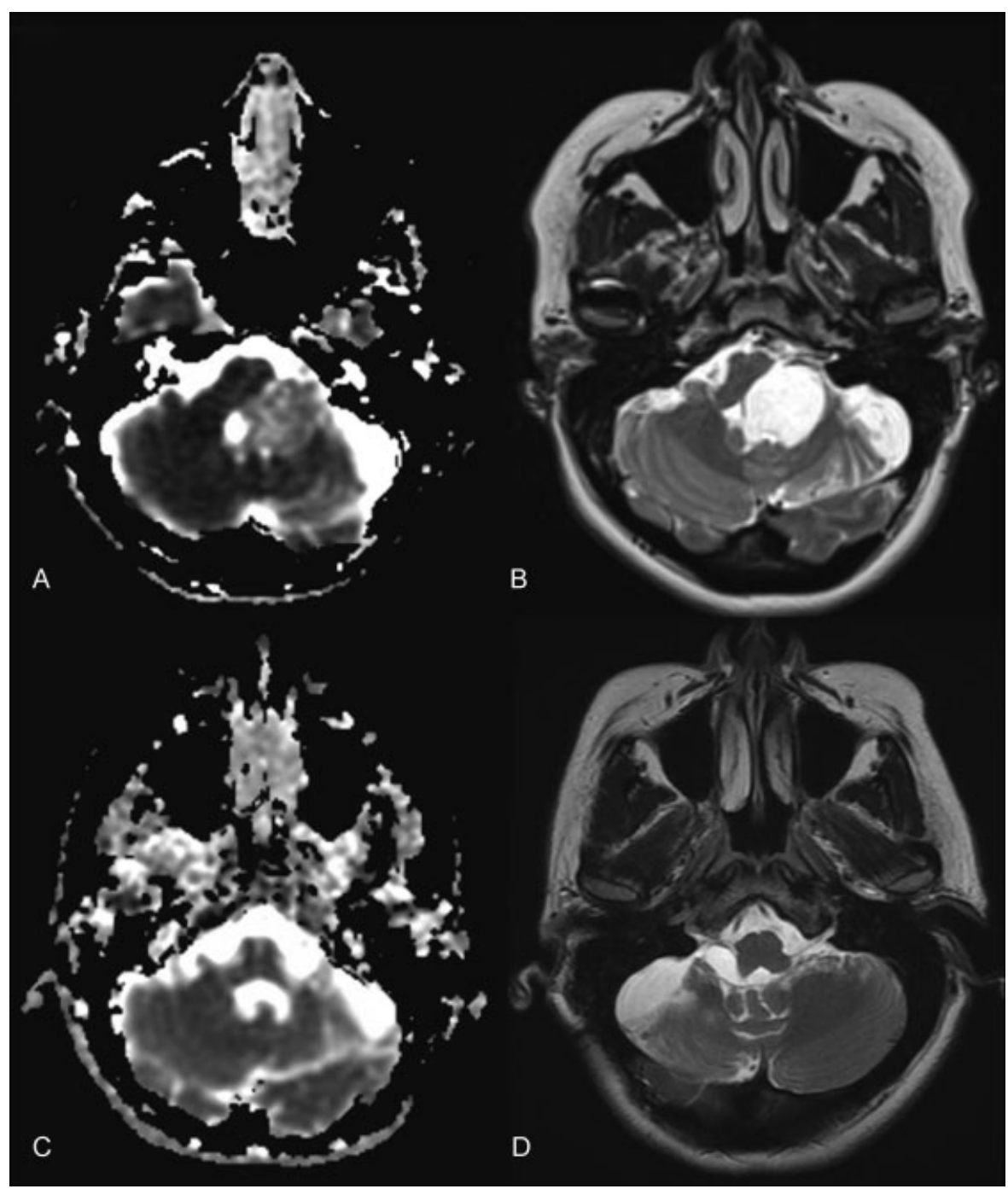

Fig. 1 Axial diffusion-weighted image $(A, C)$ and axial T2 magnetic resonance imaging (MRI) (B,D) showing large epidermoid cyst of the left cerebellopontine angle, brain stem, and foramen of Luschka before $(A, B)$ and after $(C, D)$ a gross total resection using a retrosigmoid approach. Intraoperatively, tumor was found compressing the fifth, seventh and eighth, and ninth and tenth cranial nerves. This patient presented to us after undergoing surgery at an outside hospital 9 years prior. Now 4 years after reoperation with routine MRI surveillance, there is no evidence of recurrence. 


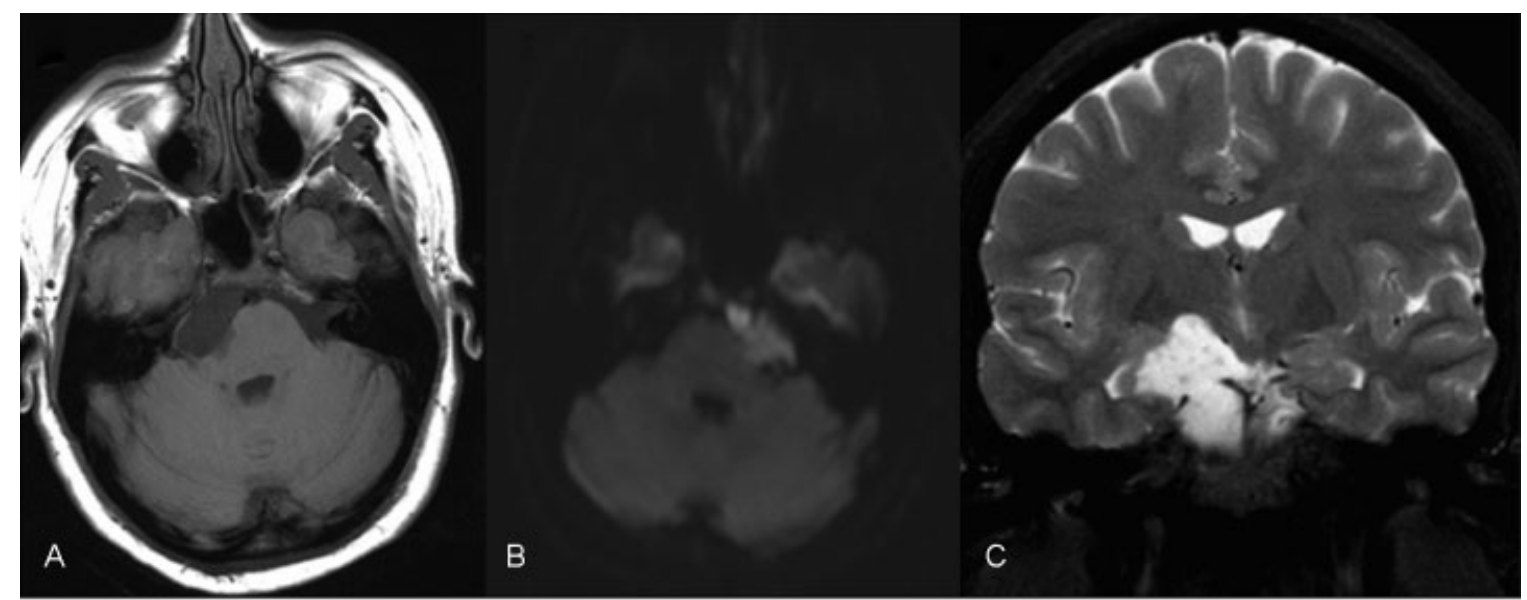

Fig. 2 Axial T1 (A), axial diffusion-weighted image (B), and coronal T2 (C) magnetic resonance imagings (MRIs) demonstrating an epidermoid cyst extending from below the internal auditory meatus to a point abutting the anterior thalamus, affecting and compressing the right cerebral peduncle, abutting the right optic radiation and hypothalamus. A petrosal approach was used in the resection of this tumor.

presenting with $\mathrm{CN}$ deficits tended to receive GTR less frequently ( 7 of $15,47 \%$ ) than patients without presenting $\mathrm{CN}$ deficits ( 9 of $13,69 \%$ ), but this difference was not statistically significant $(p=0.23)$. However, patients presenting with $\mathrm{CN}$ deficits who underwent STR were more likely to have improved CN function than those with GTR $(p=0.02)$. Regardless of extent of resection or status of preoperative $\mathrm{CN}$ function, no patient in our series endured new $\mathrm{CN}$ deficits following surgery.

Including procedures at outside hospitals, 10 of 28 (36\%) patients required second operations. Four of them underwent a GTR during their second procedures. One of these patients presented to us from an outside hospital, while the other three were previously operated on at our institution. Reoperations for epidermoid cysts that received their primary resection at our institution were performed at an average $3.6+/-1.8$ years following the initial operation, which was shorter than the interval for those presenting from outside hospitals ( $13+/-7.5$ years).

Four patients experienced hydrocephalus postoperatively. Two of these patients' tumors were located in the fourth ventricle and two were in the petrosal apex. All underwent subsequent surgery for placement of ventriculoperitoneal shunts. Unfortunately, one of these patients developed bacterial meningitis following multiple proce-

Table 2 Skull base approaches used to access and resect epidermoid cysts

\begin{tabular}{|l|l|}
\hline Surgical approach & Number of cases \\
\hline Retrosigmoid & 16 \\
\hline $\begin{array}{l}\text { Combined transpetrosal and } \\
\text { retrosigmoid approach }\end{array}$ & 5 \\
\hline Transpetrosal & 5 \\
\hline Middle fossa & 2 \\
\hline
\end{tabular}

dures for her epidermoid cyst and shunt placement surgery for hydrocephalus.

\section{Discussion}

Epidermoid cysts are slow-growing, benign tumors that originate during gestation but typically present between 20 and 40 years old. ${ }^{2,3,9-11}$ They are believed to grow at a linear rate similar to that of normal epidermis and symptoms may take years to manifest. ${ }^{2,7}$ Even though this is benign tissue, symptoms occur due to neurovascular compression from tumor mass effect and indicate the need for removal. ${ }^{12,13}$ The majority of epidermoid cysts occur in the CPA and the posterior fossa where they may cause a breadth of symptoms related to dysfunction of the $\mathrm{CN}$. $^{14,15}$

Epidermoid cysts often cause $\mathrm{CN}$ deficits through compression, adherence and even complete encasement of the respective nerves. ${ }^{3,16,17}$ In one study, $83 \%$ of patients had some $\mathrm{CN}$ deficit prior to surgery. ${ }^{8}$ The extent of $\mathrm{CN}$ involvement can usually be determined by the preoperative symptoms, such as facial drooping and trigeminal neuralgia. A previous report demonstrated that the incidence of $\mathrm{CN}$ dysfunction occurred most often in CN VIII (73\%), CN V (56\%), and CN VII (24\%), consistent with other tumors of the CPA where epidermoid cysts occur most frequently. ${ }^{16}$ Another study found that most of its patients presented with preoperative deficits of the trigeminal nerve, and these deficits persisted postoperatively more often than other $\mathrm{CN}$ deficits. ${ }^{17}$ Preoperative $\mathrm{CN}$ deficits might also hint at the development of the tumor. Symptoms such as facial palsy tend to manifest at earlier stages compared with other $\mathrm{CN}$ deficits. ${ }^{18}$ The rate of permanent deficits depends on the degree that the tumor adheres to the neurovascular structures. ${ }^{3,19,20}$ Patients with these symptoms may warrant more conservative resections, so as not to inflict further $\mathrm{CN}$ damage.

The goal of epidermoid cyst removal surgery is GTR with the preservation of surrounding $\mathrm{CN}$, vasculature, and brain 
parenchyma. ${ }^{21}$ Strong controversy exists over the extent of epidermoid cyst removal, as many surgeons do not support total removal. ${ }^{18,22,23}$ GTR has been suggested to prevent a recurrence, but some studies have shown that patients with GTR still do recur. ${ }^{23}$ In patients with total removal, the rate of tumor regrowth is lower than those patients with a STR. ${ }^{24}$ The downside of a GTR is that it is very surgically challenging due to the epidermoid cyst's ability to adhere to surrounding neurovascular structures. ${ }^{3,8,12,25}$ Meticulous dissection with removal of the capsule from these structures can lead to permanent neurological deficits. Thus, many authors argue for STR when adherence to vital structures is demonstrated. $3,9,21,22,24,26-28$

If the adherence to the neurovascular structures is too extensive, then a STR of the cyst and any capsule that is nonadherent is performed. ${ }^{2,5}$ This procedure decompresses the surrounding area, hopefully relieving the patient of any neurological symptoms. However, STR leaves the patient at a higher risk of tumor recurrence which would require surgery if it becomes symptomatic. ${ }^{9}$ Due to the slow growth of the tumors, symptoms might not reoccur for several years. ${ }^{3}$ One study showed that $30 \%$ of their patients who underwent a STR experienced a recurrence, and patients who underwent a reoperation did so at an average of 8.1 years after initial excision. ${ }^{24}$ Other reports have shown a recurrence time of up to 30 to 40 years. $^{3}$

We report a higher reoperation rate $(70 \%)$ for patients with STR at a shorter interval (3.6 years) than these studies, which may be due to closer follow-up for patients with known residual tumor. Additionally, we show that residual epidermoid cysts can be safely and even definitively treated with subsequent treatment. Three patients in our series underwent GTR following an initial STR. This may be because during primary operations, it is unclear whether the pockets of residual tumor left behind will grow, but knowing something about their proliferation as well as their neuroanatomical location allows for a more aggressive resection in select cases on the second try. Nonetheless, the associated risk involved with recurrences is not minimal. ${ }^{6}$ The risks of any reoperation, such as infection and operative morbidity, are present as seen in one patient in our series who developed aseptic meningitis after operation for a residual tumor. One report demonstrated an epidermoid cyst that underwent STR and transformed into squamous cell carcinoma. ${ }^{29}$ While this risk is very low, it demonstrates the need for close patient follow-up after a STR. ${ }^{30,31}$ Despite shorter recurrence intervals than reported in the literature, we emphasize the importance of indefinite MRI surveillance for patients with residual epidermoid cysts, as demonstrated by three patients in our series with recurrences at greater than 5 years after their initial surgery.

\section{Conclusion}

Complete resection of epidermoid cysts should remain a high priority of therapy, but, based on our findings, preservation of $\mathrm{CN}$ function should be a primary goal, determining the extent of resection. Utilization of careful surgical technique and intraoperative monitoring may maximize extent of resection and preservation of $\mathrm{CN}$ function. Due to the impact $\mathrm{CN}$ deficit has on quality of life, it is crucial to carefully consult patients of this risk ahead of time, while emphasizing the necessity of long-term follow-up in cases of STR.

\section{References}

1 Akar Z, Tanriover N, Tuzgen S, Kafadar AM, Kuday C. Surgical treatment of intracranial epidermoid tumors. Neurol Med Chir (Tokyo) 2003;43(06):275-280, discussion 281

2 Patibandla MR, Yerramneni VK, Mudumba VS, Manisha N, Addagada GC. Brainstem epidermoid cyst: an update. Asian J Neurosurg 2016;11(03):194-200

3 Berger MS, Wilson CB. Epidermoid cysts of the posterior fossa. J Neurosurg 1985;62(02):214-219

4 Kato K, Ujiie H, Higa T, et al. Clinical presentation of intracranial epidermoids: a surgical series of 20 initial and four recurred cases. Asian J Neurosurg 2010;5(01):32-40

5 Mohanty A, Venkatrama SK, Rao BR, Chandramouli BA, Jayakumar PN, Das BS. Experience with cerebellopontine angle epidermoids. Neurosurgery 1997;40(01):24-29, discussion 29-30

6 Nagasawa D, Yew A, Safaee M, et al. Clinical characteristics and diagnostic imaging of epidermoid tumors. J Clin Neurosci 2011;18 (09):1158-1162

7 Alvord EC Jr. Growth rates of epidermoid tumors. Ann Neurol 1977;2(05):367-370

8 Safavi-Abbasi S, Di Rocco F, Bambakidis N, et al. Has management of epidermoid tumors of the cerebellopontine angle improved? A surgical synopsis of the past and present. Skull Base 2008;18(02): 85-98

9 Chowdhury FH, Haque MR, Sarker MH. Intracranial epidermoid tumor; microneurosurgical management: an experience of 23 cases. Asian J Neurosurg 2013;8(01):21-28

10 Keville FJ, Wise BL. Intracranial epidermoid and dermoid tumors. J Neurosurg 1959;16:564-569

11 DeMonte F, Gilbert MR, Mahajan A. In: Tumors of the Brain and Spine. Houston, TX: Springer Verlag; 2007 SBN:0387292012

12 Gopalakrishnan CV, Ansari KA, Nair S, Menon G. Long term outcome in surgically treated posterior fossa epidermoids. Clin Neurol Neurosurg 2014;117:93-99

13 Li F, Zhu S, Liu Y, Chen G, Chi L, Qu F. Hyperdense intracranial epidermoid cysts: a study of 15 cases. Acta Neurochir (Wien) 2007;149(01):31-39, discussion 39

14 deSouza CE, deSouza R, da Costa S, et al. Cerebellopontine angle epidermoid cysts: a report on 30 cases. J Neurol Neurosurg Psychiatry 1989;52(08):986-990

15 Kobata H, Kondo A, Iwasaki K. Cerebellopontine angle epidermoids presenting with cranial nerve hyperactive dysfunction: pathogenesis and long-term surgical results in 30 patients. Neurosurgery 2002;50(02):276-285, discussion 285-286

16 Kobata H, Kondo A, Iwasaki K, Nishioka T. Combined hyperactive dysfunction syndrome of the cranial nerves: trigeminal neuralgia, hemifacial spasm, and glossopharyngeal neuralgia: 11-year experience and review. Neurosurgery 1998;43(06):1351-1361, discussion 1361-1362

17 Hasegawa M, Nouri M, Nagahisa S, et al. Cerebellopontine angle epidermoid cysts: clinical presentations and surgical outcome. Neurosurg Rev 2016;39(02):259-266, discussion 266-267

18 Yaşargil MG, Abernathey CD, Sarioglu AC. Microneurosurgical treatment of intracranial dermoid and epidermoid tumors. Neurosurgery 1989;24(04):561-567

19 Samii M, Tatagiba M, Piquer J, Carvalho GA. Surgical treatment of epidermoid cysts of the cerebellopontine angle. J Neurosurg 1996;84(01):14-19

20 Vinchon M, Pertuzon B, Lejeune JP, Assaker R, Pruvo JP, Christiaens JL. Intradural epidermoid cysts of the cerebellopontine angle: 
diagnosis and surgery. Neurosurgery 1995;36(01):52-56, discussion $56-57$

21 Schiefer TK, Link MJ. Epidermoids of the cerebellopontine angle: a 20-year experience. Surg Neurol 2008;70(06):584-590, discussion 590

22 Altschuler EM, Jungreis CA, Sekhar LN, Jannetta PJ, Sheptak PE. Operative treatment of intracranial epidermoid cysts and cholesterol granulomas: report of 21 cases. Neurosurgery 1990;26 (04):606-613, discussion 614

23 Long DM. Intracranial epidermoid tumors. In: Apuzzo ML, ed. Brain Surgery: Complication Avoidance and Management. New York, NY: Churchill Livingstone; 1993:669-688

24 Talacchi A, Sala F, Alessandrini F, Turazzi S, Bricolo A. Assessment and surgical management of posterior fossa epidermoid tumors: report of 28 cases. Neurosurgery 1998;42(02):242-251, discussion 251-252

25 Baumann $\mathrm{CH}$, Bucy PC. Paratrigeminal epidermoid tumors. J Neurosurg 1956;13(05):455-468
26 Gagliardi FM, Vagnozzi R, Caruso R, Delfini R. Epidermoids of the cerebellopontine angle (cpa): usefulness of CT scan. Acta Neurochir (Wien) 1980;54(3-4):271-281 (wien)

27 Lunardi P, Missori P, Innocenzi G, Gagliardi FM, Fortuna A. Long-term results of surgical treatment of cerebello-pontine angle epidermoids. Acta Neurochir (Wien) 1990;103(3-4): 105-108

28 Salazar J, Vaquero J, Saucedo G, Bravo G. Posterior fossa epidermoid cysts. Acta Neurochir (Wien) 1987;85(1-2):34-39

29 Chon KH, Lee JM, Koh EJ, Choi HY. Malignant transformation of an epidermoid cyst in the cerebellopontine angle. J Korean Neurosurg Soc 2012;52(02):148-151

30 Garcia CA, McGarry PA, Rodriguez F. Primary intracranial squamous cell carcinoma of the right cerebellopontine angle. J Neurosurg 1981;54(06):824-828

31 Hamlat A, Hua ZF, Saikali S, et al. Malignant transformation of intra-cranial epithelial cysts: systematic article review. J Neurooncol 2005;74(02):187-194 